\title{
US high-energy physics plans hot up with supercollider go-ahead
}

\section{Washington}

THE jewel in the high-energy physics crown, the Superconducting Super Collider (SSC), took a step closer to reality last week. Energy Secretary John Herrington announced last Friday that President Reagan is giving full support to building SSC, and that the administration will ask for the funds to start the $\$ 4,400$ million project in 1988.

Final presidential approval for the project came after a meeting of the Domestic Policy Council last Thursday. Although Herrington had announced last year that he supported the project (see Nature 324, $502 ;$ 1986), the White House has been conspicuously silent. There was, for example, no mention of the project in the 1988 budget request last month nor in the president's State of the Union address last week.

Herrington said a decision on how a site for SSC will be selected will be announced on 10 February. Details of how the project will be financed will also then be spelled out. Herrington speculates that the 1988 budget request for SSC will be approximately $\$ 60$ million.

Presidential approval by no means makes construction of SSC a certainty. Congress must be convinced that SSC's scientific and political rewards outweigh the financial obligations.

SSC is seen as necessary for the next generation of high-energy physics. The present generation of accelerators has produced proton-antiproton collisions at energies up to 1.8 million million electron volts $(1.8 \mathrm{TeV})$, but SSC will make possible proton-proton collisions at energies up to $40 \mathrm{TeV}$, when fundamental properties of matter now hidden should be revealed by peaks in the interaction crosssection of the particles and in the products of their collisions.

To achieve such high energies, SSC will have a main ring $82.94 \mathrm{~km}$ in circumference lined with approximately 10,000 superconducting magnets. SSC will consist of two concentric rings, each capable of accelerating protons up to $20 \mathrm{TeV}$. There will be four points along the accelerator circumference where the two beams can intersect, allowing collisions. The design for SSC was coordinated by the Central Design Group, at Lawrence Berkeley Laboratory in California. The Department of Energy will be the principal federal agency in the project. The Energy Department now provides 90 per cent of the support for high-energy physics research in the United States.

Although the decision to build SSC is unilateral, Herrington said the United States plans to "seek maximum cost- sharing funding from other countries", as well as contributions from private industries and local governments. But whatever the level of international enthusiasm, Herrington stresses that SSC is "an American project, with American leadership, and we're going forward with it".

Choosing a site for SSC is bound to be a political free-for-all. More than half the states in the Union have announced an interest in the project, some spending millions of dollars to make an attractive bid. The state that wins the prize will reap an economic windfall from the construction

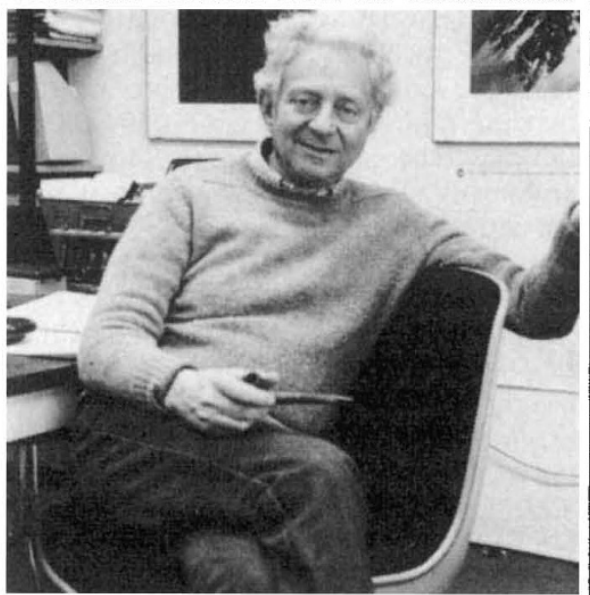

Fermilab director Leon Lederman faces the inevitable cash shortage.

of a project the size of SSC, not to mention enhanced prestige.

But even as the Reagan administration turns its sights towards the future of highenergy physics, two new machines are getting ready to start full-scale operations. At Fermi National Accelerator Laboratory (Fermilab) outside Chicago, the Tevatron has begun producing protonantiproton collisions after a shutdown for repairs.

In the fall of 1985, the Collider Detector at Fermilab (CDF) recorded the first 1.8$\mathrm{TeV}$ collisions produced by the Tevatron. Now a 3-m central tracking chamber just commissioned will allow precise tracking of particles produced in collisions. The Tevatron produced low-intensity collisions last December, and now both CDF and Tevatron are being debugged. So far, says to Fermilab's Hans Jensen, beam luminosity has been "quite modest", but he expects that will improve by the time full power operations begin in March.

The other new machine expected to begin operations this year is the Stanford Linear Collider (SLC) in Palo Alto, California. According to project administrator Don Getz, both positron and electron beams have reached design energies of 50 thousand million electron volts $(50 \mathrm{GeV})$, and he expects both beams will be into the

\section{Johns Hopkins atop spending table}

\section{Washington}

THE table below shows the top ten US universities ranked by federal research funds received in fiscal year 1985 , based on data in a recent report from the National Science Foundation. Johns Hopkins owes its ranking to the $\$ 299$ million a year that went to its Applied Physics Laboratory, a mostly independent defence research facility counted in the university total only since 1978. Similar independent research facilities at the Massachusetts Institute of Technology, Stanford University and Cornell University are not included in the totals.

US university research and development during 1985

Institution

Johns Hopkins University

Massachusetts Institute of

Technology

Stanford University

University of Washington

University of California,

Los Angeles

Columbia University

(main division)

University of Wisconsin,

Madison

Federal funds (\$ million)

429.18

Cornell University

Harvard University

Yale University

187.65

189.96

146.18

124.60

119.97

109.41

109.23

Most federal funds for research in $\mathbf{1 9 8 5}$ came from 15 agencies. Topping that list is the Department of Health and Human Services $(\$ 3,098.6$ million $)$, followed by the Department of Defense (\$1,040.8 million), then the National Science Foundation (\$1,011.1 million) and the Department of Energy (\$373.1 million). Total federal spending on research and development in universities and colleges in 1985 was $\$ 6,379 \cdot 2$ million.

Joseph Palca

final focus by the end of February. The primary detector will be installed in April, and Getz hopes to start seeing $\mathrm{Z}$ bosons in May. Getz says SLC will begin operating at a luminosity well below design capability, but even at 1,000 times below design specifications he expects $15-20 \mathrm{Zs}$ a day.

Funds will be a problem for both facilities. Getz admits that the money available will not allow SLC to be operated as much as he would like. Leon Lederman, Fermilab's director, also faces difficult financial decisions in operating the Tevatron.

Although enthusiasm for SSC abounds throughout the high-energy physics community, physicists are anxious that its financing should be truly independent from continuing projects. Alvin Tollestrup, co-leader of CDF, says SSC is the "obvious next step" for the future. But, says Tollestrup, siphoning funds from experiments already in place to pay for SSC would be "a disaster". Joseph Palca 